\title{
Focus Shift and Outsourcing in University
}

\section{Libraries' Acquisition and Cataloguing}

\author{
Chunlan Qiu \\ Library Jiangxi University of Science and Technology, Ganzhou 341000, China \\ E-mail: jxust@126.com \\ Yonglin Xiao \\ Library Jiangxi University of Science and Technology, Ganzhou 341000, China
}

\begin{abstract}
Focus shift and outsourcing in university libraries' acquisition and cataloguing, which are the trends of re-composition and optimized allocation of social resources in market mechanism, will help to improve the quality of document construction as well as the efficiency of acquisition and cataloguing and allocate human resources in a more reasonable way. Nowadays, outsourcing of books has become usual practice in libraries. It should be the future focus to construct scientific and reasonable collection structure, acquire books in different channels, forms and at different levels and to extend acquisition and cataloguing services.
\end{abstract}

Keywords: University library, Acquisition and cataloguing, Outsourcing, Document resources construction, Market mechanism, Human resources allocation

\section{Introduction}

It is the difficult as well as key point for libraries to construct their resources in a scientific and reasonable way and to improve the rate of protection and utilization of these resources. At $1^{\text {st }}$ National Seminar on Document Acquisition held in Kunming in2005, the issues of "digital document resources Acquisition" and "how to relocate the cataloguing department" were put forward to call on a joint effort for solutions. Library acquisition should be supported in theory, through which all libraries' successful experience and patterns can be learned and perfected by others. From our library beginning to outsource some services in 2004 to our acquisition of over 350,000 foreign and Chinese books (including 160,000 special offers) and then to our inspection of 320,000 processed books, there has been no increase in the acquisition and cataloguing staff. What's more, there has been obvious improvement in the quality of processing and cataloguing data and acquisition has had richer forms and more profound contents. Although the issue on outsourcing is on longer new for us, it is still necessary to explore it from the perspectives of reasonable allocation of social resources, re-composition of acquisition service and reasonable allocation of human resources in market mechanism.

Originating from industrial enterprises in 1980s, outsourcing has been an innovative management method. By employing this strategy effectively, enterprises are able to avoid unlimited expansion, and achieve their goals of downsizing and paying more attention to their professional fields. Not until the middle and late 1980s did outsourcing begin to be accepted by most libraries. In the west, many libraries outsource their routine tasks, such as cleaning, security guard, unpacking, attaching labels, binding, putting book onto and off shelves. Furthermore, they even outsource some professional tasks to some professional companies, such as data base construction, computer system management and equipment maintenance and so on. This service reached its peak in the middle and late 1990s, when the outsourcing of a whole library caused heated controversy. In China, outsourcing began to be employed in the 1990s with its focus mainly on routine tasks and catalogue compilation.

\section{Practice and Experience of Outsourcing in Libraries}

Here outsourcing in libraries means that some services in libraries are entrusted to the middlemen according to contracts. Outsourcing can be achieved in interviewing, catalogue compiling, processing, periodical binding, cleaning and security guard, management of reading rooms and so on (Fucheng Zhu, 2000). Employing this method, all processing services, including attaching magnetic stripes, stamping, fixing bar codes and labels and so on, will be done by the middlemen. In most cases, the middlemen organize their staff to work on the spot, whose work will be examined by the library staff in order to improve their efficiency and processing quality. However, an out-of-town middleman will have to deal with the whole processing course in his place, hence lacking in libraries' control and examination.

During the outsourcing course, libraries are expected to undertake some tasks such as planning, laying down goals 
and standards, monitoring, evaluating quality and perfecting processes and so on. All in all, the following aspects should be included:

Libraries are expected to assess the middlemen's credit, including their finance, human resources, credit, management control and efficiency, service quality, price and so on.

How to choose a middleman is quite important for the final result of the outsourcing practice. To be more specific, quite a few aspects of a middleman should be taken into consideration, including its scale, staff number, reputation, efficiency, service quality, work experience, professionals in processing, after-sale services, price and so on. In addition, management of the whole outsourcing process, especially the technical part should be attached much importance to. And an efficient feedback system should be set up to realize timely communication and adjustment.

Libraries should be careful in signing their outsourcing contracts, which include their goals, the expected profit, the category of cooperation, operational methods, division of duties, ownership, amendment and suspension of the contracts, payment, compensation and so on. Actually, libraries should include the processing service in their contracts when inviting public bidding for book acquisition. When checking the processed books, overall quality management should be employed and the national standard for books as well as libraries' internal standard for books should be referred to.

They are also expected to monitor the quality of processing. First, they should lay down some detailed rules for book processing according to the real situations, including the deadline, the position to attach labels and bar codes, the position and number of stamps, the number, brand and function of magnetic stripes, the position to put the table of returning deadlines, the disposal of enclosed disks and so on; second, they should give the middlemen some book samples for their references in rough and refined processing; third, the checking staff in libraries should examine the roughly-processed books (with magnetic stripes, stamps, bar codes and so on) and return those with problems; fourth, after finishing the compilation of catalogues and collecting, some refined processing tasks should be finished. In addition, the circulation department should check the processed books again finally to guarantee the processing quality.

They are also expected to do something in the economic accounting of cost and profit as well as communicative tasks. Before outsourcing their services, libraries should have a detailed analysis about the tasks and their human resources and reach a conclusion about which services are not so closely related to their core business, which services are difficult for them to complement, or which services will cost them too much and so on. After outsourcing their services, instead of getting out of touch, they should keep a close eye on the whole processing course to conduct supervision and management when necessary. (Fenge Wang, 2006) In addition, a feedback system, including suggestion boxes, electronic bulletin boards and comment boards and so on should be set up to enable readers to communicate with libraries. Due to the mutual benefit shared by libraries and the middlemen, they are expected to understand each other and increase their cooperation in order to ensure the smooth development of their services.

In short, the following goals should be achieved in outsourcing: not involving the management of libraries; encouraging the external positive factors and taking full advantage of human resources of the whole society; helping to reduce the cost and time spent in acquisition and cataloguing and therefore accumulating time and effort to achieve the construction of document resources.

\section{Shifting Work Focus to Acquisition}

With the adoption of outsourcing, libraries will shift their focus to acquisition, and accordingly, the acquisition and cataloguing department will be able to pay more attention to the construction of document resources following universities' requests in teaching, research and the construction of branches. Three conversions should be achieved with great effort.

\subsection{Constructing Scientific and Reasonable Collection Structure}

When purchasing books, some surveys about collection structure, the utilization of books, the ratio of teachers to students, development of scientific branches should be conducted and the offered specialties and the construction of key branches should be referred to to form a plan for the year's document resources construction. In order to form special collection characteristics, the structure of current document resources, different document types, different periods should be analyzed and then some special document resources should be purchased with the regional, resource and academic advantages. In addition, the percentage of students from different departments as well as their demands for books should be taken into consideration when planning for book acquisition. The number of copies should also be laid down according to the above information. For example, our university is professional in science with meteorology as a long-established major. Accordingly, in our plan for book collection, books on 
atmospheric environment should be collected thoroughly; those on some key branches such as computer technology and electronic communication should be collected as an important part; those on mathematics, management, electronic business should be increased reasonably and those on literature and arts can be collected in an average number.

\subsection{Shifting to Acquisition in Various Channels, Forms and at Different Levels}

In order to improve the pertinency of our document resources acquisition, the systems of "acquisition in different branches" and "books chosen by experts" should be conducted with great effort. According to the former system, acquisition should be made in different branches of study. The acquisition staff is expected to collect those printed and digital document resources and purchase the ownership and utilization of these resources related to different branches. According to the latter, some consultants with passion in document construction, academic specialty in different fields and ability to grasp the trends of researches in their specialties will be chosen to give some advice on what books to choose. In this way, libraries are expected to break the former way in which the acquisition staff was divided according to document types and different languages. Rather, the acquisition staff divided according to different academic fields should form dynamic acquisition groups together with the committee of libraries and the experts in different fields to finish the acquisition task together. The acquisition staff of libraries should try to collect as much information about books as possible, classify it according to the key words provided by different departments and deliver it to experts in different departments or sometimes experts deliver the information about the demanded books to the relevant acquisition staff to put them in the purchase plan. In this way, experts' enthusiasm for choosing books will be encouraged, and the utilization degree of the collected books will be increased as well. In addition, in the purchasing course, publishing houses should take dominance with suppliers serving as an auxiliary part. On one hand, it will take us less time and energy to get most books we need by turning to publishing houses as the main sources; on the other hand, suppliers will help us to find those document resources published by minor publishing houses in a short time.

\subsection{Extending Acquisition and Cataloguing in Various aspects}

First comes the extension in the ways of acquisition. Online acquisition (searching for document information--selecting and ordering--- placing an order--- payment--- receiving document resources) can be used to shorten the purchasing period, hence more convenient and faster than the traditional ways. Second is the extension in the channels to learn about readers' feedback. The former ways to have face-to-face surveys or fill in forms suffered from low efficiency, low accuracy, too many omissions and failures to satisfy readers' demands. Instead, readers' demands for books can be learned about through online forums, E-mail and BBS with high speed and high efficiency. Therefore, their demands tend to be satisfied better now. Third is the extension in catalogued materials. For example, disordered online information resources can be arranged to ensure their correctness and availability; the cataloguing of relevant information in collection shows certain document's location in various carriers and links to relevant information. Some fields in MARC such as 307,753,856 should be put importance to in association searching in order to reveal the relevance among different document resources. Last is the extension in cataloguing objects. On one hand, cataloguing members will have greater convenience to process, describe and reveal document resources in a more profound way; on the other hand, readers' deep-level demands to search for documents thoroughly and acquire relevant information more conveniently will be fulfilled.

\section{Problems and Countermeasures in Focus Shift and Outsourcing}

Nothing can be perfect, neither is outsourcing. Although it plays a quite important role in the improvement of efficiency and core competitiveness, it also suffers from some problems. For example, the acquisition and cataloguing staff will rely too much on the external technical power with a lot of services outsourced to the middlemen; with the cataloguing staff hired by the middlemen delivering and cataloguing document materials for clients, the books and data can be matched well but the unsteady quality of catalogued data will influence the standardization of cataloguing formats; the data collected by some authoritative institutions, such as China National Library, has been out of date in spite of its reliable quality; different middlemen process document resources in the same place at the same time, causing the possible occurrence of errors resulted from carelessness. In order to solve these problems, overall quality management should be conducted in the outsourced minor services. Adopting the idea of "systematic project", the relevant departments should try to refine the operational flow and carry out "quota management" and guarantee orderly taking-over procedures. Special importance should be attached to data quality management, in which a permitted error rate is given and a universal standard for quality management should be given when using external data. To be more specific, Book Classification in China National Library can be used for classification indexes of Chinese books and Chinese Subject Thesaurus can be used for subject indexes. In addition, China Machine Readable Catalogue Handbook (CNMARC) can be employed to register Chinese document data, to check the copied data word by word and correct errors or contents not in conformity with the library's detailed rules 
and to expand the collection according to the reality. What's more, libraries should keep constant touch with the middlemen to guarantee the average checking amount and publishing amount of documents every month. When paying for services, the quality standard should be stuck to first.

\section{Evaluation and Prospects}

By turning to focus shift and outsourcing in libraries' acquisition and cataloguing, we are integrating and optimizing our social resources in market mechanism in order to improve libraries' efficiency and realize a management model in which libraries and the middlemen cooperate with their respective advantages. In spite of some problems in the present outsourcing practice of libraries, it reflects the trends for the re-division of some library functions. With the modernization and networking of libraries, the increase in the proportion of virtual collections and the popularity of online cataloguing, the staff in processing and data processing will give way to those in developing deep-level resources and guaranteeing document information. Actually, the outsourcing practice will not only encourage libraries to think over how to save their costs and improve their efficiency but also help them to renovate their operational processes and conduct their re-composition. With the changes in libraries' functions in this information era, it is an inevitable trend for modern libraries to shift their focuses and outsource their services. It is believed that outsourcing will have greater scope for development with the modernization of university libraries now and in the future.

\section{References}

Rao, Sijun. (2004). Talking about the Subcontract of Library Work. Science and Technology Information Development and Economy. 14 (6):65- 66

Wang, Fenge. (2006). Talking about the Subcontract of University Libraries' Catalog Work. Science and Technology Information Development and Economy. 16(3):77-78

Zhu, Fucheng. (2000). Success, Failure and Revelation in Outsourcing of American Libraries. Journal of Academic Libraries. 2000 (1): 30- 32 